\title{
Research on improving development effect of high-saturated reservoir in the late stage of water-flooding
}

\author{
Xiaoying Shi ${ }^{*}$, Huajiao Guan ${ }^{1}$, Hui Zhao ${ }^{1}$, Yali Jiang ${ }^{2}$, Yuying $\mathrm{Li}^{1}$ and Zhao Xue \\ ${ }^{1}$ Exploration and Development Research institute of HuaBei Oilfield Company, Renqiu 062552, China \\ ${ }^{2}$ The Fourth Exploit Factory of HuaBei Oilfield Company, Langfang 065000, China \\ ${ }^{3}$ Youxin Exploration and Development Services Co. Ltd of Huabei Oilfield Company, Renqiu 062552, China
}

\begin{abstract}
High-saturated reservoir is characterized by high saturation pressure and high gas-oil ratio. The effects of water flooding are easily influenced by the formation pressure and GOR, especially at the late stage. This article presents the relationship between the reasonable pressure maintenance level and GOR as well as water cut based on the actual characteristics of high-saturated reservoir. Then, the reservoir numerical simulation method is used to analyse the influence of pressure recovery rate and water cut rise under different injection-production ratios and injection-production methods. Research results show that the pressure maintenance level of high-saturated reservoir is larger than normal reservoirs. Bigger injectionproduction ratio results in not only faster pressure recovery rate but also higher water cut. Cyclic injection and production method under the maximum injection rate and liquid extraction amount can enhance oil recovery rate and control water cut rise at the same time, which plays a significant role in improving the development effect of water-flooding in high-saturated reservoirs at the late stage.
\end{abstract}

\section{Introduction}

Because of high-saturated reservoir with high saturation pressure and small formation-saturation pressure difference, the effects of water flooding are easily influenced by the formation pressure maintenance level. At the late period of development, the formation pressure is always below saturation pressure, the underground fluid degases severely, which will lead to declination of liquid and oil production index, substantial change of fluid viscosity. So it is very important to maintain reasonable formation pressure level, and find out suitable injection and production method to improve the development effect of water-flooding in highsaturated reservoirs at the late stage.

At presents, a number of related researches about reasonable timing of water injection, reasonable injection-production ratio and oil production rate were carried out, and these researches are mainly aimed at the initial stage of development by preventing the formation pressure from falling below the saturation pressure [1-4]. At the late stage, available studies mainly focus on enhancing oil recovery by gas injection [5-8], and it is lack of studies related to improving development effect of water injection, which is the most benefit and practical way. This article presents the relationship between the reasonable pressure maintenance level and GOR as well as water cut based on the actual characteristics of high-saturated reservoir. Then, reservoir numerical simulation method is used to analyse the influence of pressure recovery rate and water cut rise at different injection-production ratio and injectionproduction method.

\section{Reasonable pressure maintenance level}

Reasonable pressure maintenance level needs to consider three factors: pump port pressure, liquid column pressure and production pressure difference. The influence of gas production should be considered when determining the reasonable pressure maintenance level for high-saturated reservoirs. If the gas-oil ratio at the inlet of the oil well pump exceeds the range allowed by the working characteristics of the pump, the fullness of the pump will decrease, and even air lock will occur. Therefore, the minimum pump port pressure under different gas-oil ratios and water cut should be determined to ensure that the pump is reasonably full and in good working condition. The relationship between pump port pressure and fullness, gas-oil ratio, and water cut is as follows.

$$
P_{p}=\frac{G O R \cdot P_{a}}{\left[\left(\frac{1}{\beta}-1\right) /\left(1-f_{w}\right)\right]+\alpha P_{a}}
$$

$P_{p}$ - Pump port pressure, $\mathrm{MPa}$;

GOR-Gas-oil ratio, $\mathrm{m}^{3} / \mathrm{m}^{3}$;

$\alpha$ - Natural gas solubility coefficient, $\mathrm{m}^{3} /\left(\mathrm{m}^{3} \bullet\right.$ $\mathrm{MPa})$; 
$P_{a} \quad$ - Standard atmospheric pressure, $0.101325 \mathrm{MPa}$;

$\beta$-Fullness of the pump, $\mathrm{f}$;

$f_{w}$-Water cut, f。

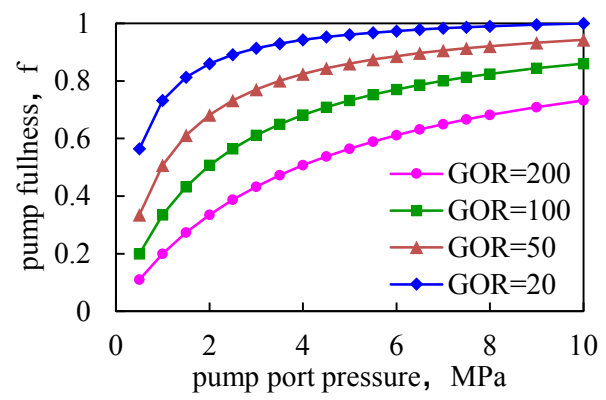

Figure 1. The relationship between pump fullness and pump port pressure under different gas-oil ratios $(\mathrm{fw}=80 \%)$.

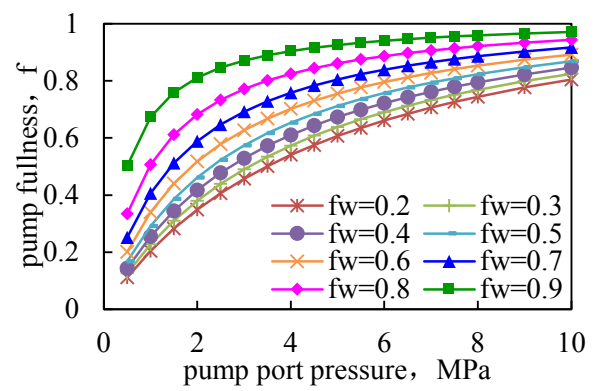

Figure 2. The relationship between pump fullness and pump port pressure under different water cut $(\mathrm{GOR}=50)$.

As can be seen from the figure that when the water cut is constant, the higher the gas-oil ratio, the higher the pump port pressure when the same pump efficiency is required. Therefore, when the liquid column pressure and the production pressure difference are constant, high-saturation reservoirs need to maintain a higher formation pressure level after degassing compared with other non-degassed reservoirs. When the gas-oil ratio is constant, the relationship between water cut and pump port pressure is just the opposite. Therefore, the pump port pressure should be maintained in a reasonable range to ensure higher pump fullness under a specific water cut and gas-oil ratio.

Taking the $\mathrm{W}$ reservoir as an example, the original formation pressure is $33 \mathrm{MPa}$, the liquid column pressure is $10.9 \mathrm{MPa}$, and the production pressure difference is $6 \mathrm{MPa}$. If the pump efficiency reaches more than $70 \%$, the pump port pressure cannot be lower than 5.5MPa, when the water cut reaches $86.7 \%$ and the gas-oil ratio is 116. So the reasonable pressure cannot be below $22.4 \mathrm{MPa}$, that is, the pressure maintenance level is not less than $67.9 \%$.

\section{Reasonable injection-production ratio}

In order to achieve a reasonable level of pressure maintenance, this paper carried out a study on a reasonable injection-production ratio. The reservoir numerical simulation method is used to analyse the influence of pressure recovery rate and water cut rise under different injection-production ratios. The total number of grid is $75 \times 50 \times 6=22500$, and the E100 model is used in eclipse, the mechanism model for highsaturated reservoirs by water-flooding is shown in Figure 3 , and the initial conditions of this model is shown in table 1 .

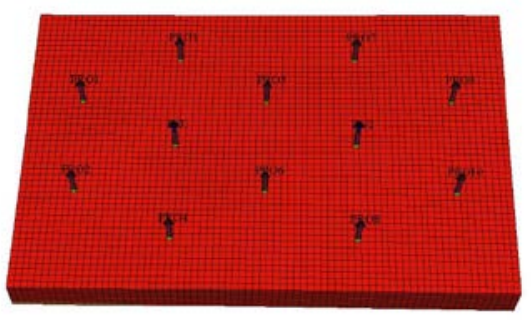

Figure 3. Mechanism model for high-saturated reservoirs by water-flooding.

Table 1. Reservoir parameters under initial conditions.

\begin{tabular}{cccccc}
\hline $\begin{array}{c}\text { Reservoir } \\
\text { Porosity }\end{array}$ & $\begin{array}{c}\text { Reservoir } \\
\text { Permeability } \\
(\mathrm{mD})\end{array}$ & $\begin{array}{c}\text { Formation } \\
\text { pressure } \\
(\mathrm{MPa})\end{array}$ & $\begin{array}{c}\text { Saturation } \\
\text { pressure } \\
(\mathrm{MPa})\end{array}$ & $\begin{array}{c}\text { GOR } \\
\left(\mathrm{m}^{3} / \mathrm{t}\right)\end{array}$ & $\begin{array}{c}\text { Original oil in place } \\
\left(10^{4} \mathrm{t}\right)\end{array}$ \\
\hline 0.23 & 35 & 30 & 24 & 164 & 72 \\
\hline
\end{tabular}

Table 2. Situation at the later stage of development simulated by the mechanism model.

\begin{tabular}{ccccccc}
\hline $\begin{array}{c}\text { Liquid } \\
\begin{array}{c}\text { Production rate } \\
(\mathrm{t} / \mathrm{d})\end{array}\end{array}$ & $\begin{array}{c}\text { Oil Production Cumulative liquid } \\
\text { rate } \\
(\mathrm{t} / \mathrm{d})\end{array}$ & $\begin{array}{c}\text { Cumulative oil } \\
\text { production } \\
\left(10^{4} \mathrm{t}\right)\end{array}$ & $\begin{array}{c}\text { Current formation } \\
\text { production } \\
\left(10^{4} \mathrm{t}\right)\end{array}$ & $\begin{array}{c}\text { possure } \\
(\mathrm{MPa})\end{array}$ & $\begin{array}{c}\text { Composite } \\
\left(\mathrm{m}^{3} / \mathrm{t}\right)\end{array}$ & $\begin{array}{c}\text { water cut } \\
(\%)\end{array}$ \\
\hline 100 & 12.4 & 36.0 & 15.7 & 12.3 & 760 & 86.3 \\
\hline
\end{tabular}

There are 10 oil wells and 2 water wells in this mechanism model. The oil well is produced in a fixed liquid rate, and the production at the later stage of development is shown in Table 2.
The research of this article is carried out on the basis of the later stage of development. Six different injection production ratio schemes were designed to predict the production situation in the next ten years. The specific content of the schemes is shown in Table 3. 
Table 3. The specific content of the six injection-production ratio schemes.

\begin{tabular}{ccccccc}
\hline Case name & Case1 & Case2 & Case3 & Case4 & Case5 & Case6 \\
\hline injection-production ratio & 0.9 & 1.0 & 1.1 & 1.2 & 1.3 & 1.4 \\
\hline
\end{tabular}

The injection-production ratios of 0.9-1.5 are analysed respectively. The simulation results in figure 46 show that when the injection-production ratio is low, the pressure recovery speed is slow, and it takes a long time to recover to a reasonable level, and the gas-oil ratio will gradually increase, which will reduce the pump efficiency. When the injection-production ratio is too large, the pressure recovery speed changes fast (recovery in a short time), and the gas-oil ratio will gradually decrease, which improves the pump efficiency, but the larger water injection volume causes the water cut rise faster.

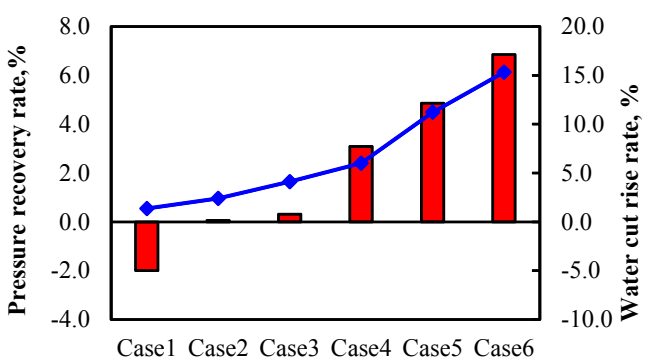

Figure 4. The influence of pressure recovery rate and water cut rise rate under different injection-production ratios.

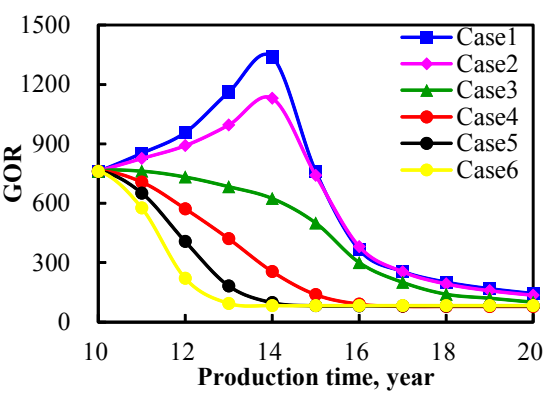

Figure 5. Gas-oil ratio change law under different injectionproduction ratios.

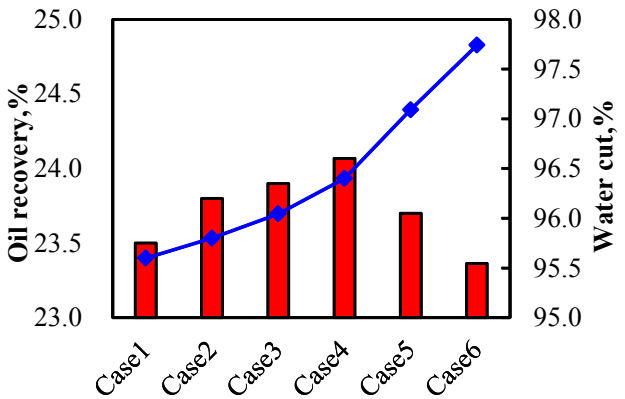

Figure 6. The influence of oil recovery and water cut under different injection-production ratios.

As the injection-production ratio increases, the degree of oil recovery first increases and then decreases. When the injection-production ratio is 1.2 , the cumulative oil production is higher and the production effect is the best. This is because when the injectionproduction ratio is relatively small, the pressure cannot be restored and continues to drop, resulting in a decline in the liquid production capacity of the oil well and a decrease in cumulative oil production. When the injection-production ratio is relatively large, the liquid volume is stable, but due to the large water injection volume, the water cut rises faster, and the cumulative oil production obtained under the same production system is reduced. Therefore, a reasonable injection-production ratio can not only quickly restore formation pressure, but also better control the rise of water content.

\section{Reasonable injection and production method}

In the late stage of high water-cut development, simply increasing the injection-production ratio cannot achieve the purpose of improving the development effect, especially in the formations with strong heterogeneity, the seepage velocity of the area with good injection water permeability is faster, and a large amount of residual oil in the low permeability area cannot be affected. Cyclic injection and production is the most economical and effective way to improve the effect of water-flooding development [9-11]. It creates unstable pressure states in the formation by periodically changing the amount of water injection and liquid production. During the pressure increase stage, the high-permeability section has higher pressure than the low-permeability section, and the oil and water flow from the highpermeability section to the low-permeability section; in the pressure reduction stage, the high-permeability section has lower pressure than the low-permeability section, and at the same time due to the capillary force and elastic force, which can drive the residual oil in the low permeability layer that cannot be displaced under the stable water injection state. Based on this principle, the paper carried out numerical simulation tests of different injection-production methods, including: cyclic water injection and cyclic injection-production methods.

\subsection{Introduction of injection and production methods}

There are several commonly used water injection methods: conventional water injection, cyclic water injection, and cyclic injection-production. In cyclic water injection method (figure 7), the water injection volume of the water well is adjusted periodically, and the oil well is produced with fixed liquid. However, in cyclic injection-production method ( figure8), the water 
injection volume of the water well and the liquid production rate are both adjusted regularly.

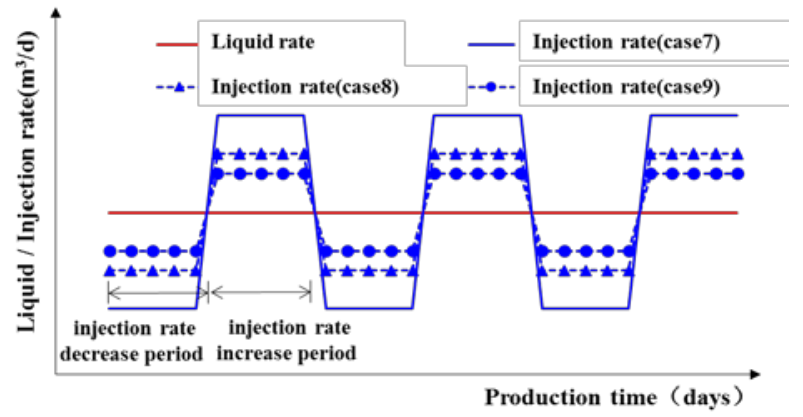

Figure 7. Schematic diagram of cyclic water injection.

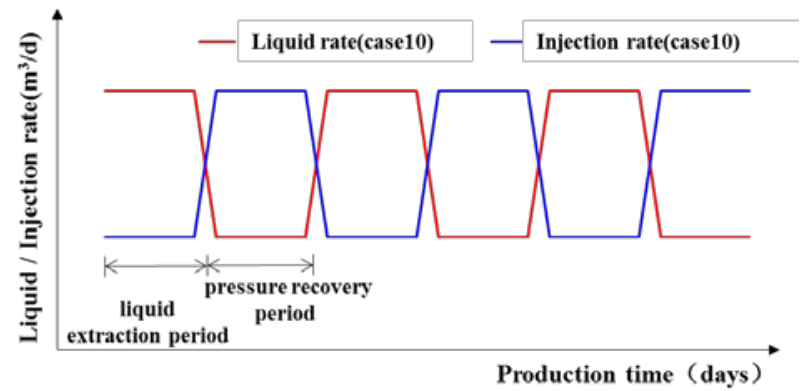

Figure 8. Schematic diagram of cyclic injection-production.

In order to study the adaptability of different water injection methods, four schemes are designed in the article under the condition of the same water injection volume in the cycle. The specific content of the scheme is shown in Table 4. Case 7 9 is cyclic water injection, and the adjustment range of the water injection volume in a cycle is different. The adjustment range of water injection volume is the largest in case 7 , and the adjustment range of water injection volume is the smallest in case 9. Case10 is the periodic injectionproduction adjustment method which liquid rate is adjusted periodically on the basis of case 7 .

Table 4. The specific content of the different water injection adjustment schemes.

\begin{tabular}{cccccc}
\hline Case name & $\begin{array}{c}\text { Injection rate } \\
\text { in first 30 days } \\
\left(\mathrm{m}^{3} / \mathrm{d}\right)\end{array}$ & $\begin{array}{c}\text { Liquid rate } \\
\text { in first 30 days } \\
\left(\mathrm{m}^{3} / \mathrm{d}\right)\end{array}$ & $\begin{array}{c}\text { Injection rate } \\
\text { in followed 30 days } \\
\left(\mathrm{m}^{3} / \mathrm{d}\right)\end{array}$ & $\begin{array}{c}\text { Liquid rate } \\
\text { in followed 30 days } \\
\left(\mathrm{m}^{3} / \mathrm{d}\right)\end{array}$ & $\begin{array}{c}\text { Total } \\
\text { injection amount } \\
\left(10^{4} \mathrm{~m}^{3}\right)\end{array}$ \\
\hline Case7 & 0 & 100 & 240 & 100 & 43.2 \\
Case8 & 48 & 100 & 192 & 100 & 43.2 \\
Case9 & 96 & 100 & 144 & 100 & 43.2 \\
Case10 & 0 & 200 & 240 & 0 & 43.2 \\
\hline
\end{tabular}

\subsection{Comparison of different injection and production methods}

The numerical simulation calculation results are shown in the figure9.

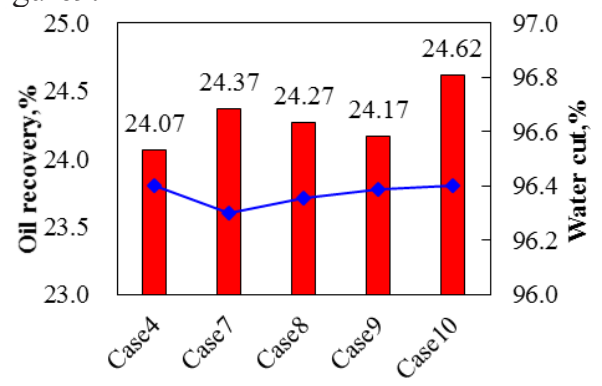

Figure 9. Oil recovery and water cut under different water injection method
It can be seen from the figure 9 that the cyclic adjustment of water injection can improve the recovery factor compared with conventional water injection methods under the same water injection conditions. However, the degree of improvement is different. The greater the adjustment range of water injection, the higher the degree of recovery at the end of the decade and the slight decrease in water cut. Further, when the water injection adjustment and the water injection cycle are the same, the adjustment of the oil well liquid rate can also affect the development effect. Case 10 increase the recovery level by $0.6 \%$, and reduce the water content by $0.1 \%$. The reason is that a larger adjustment range of the water injection volume can cause larger pressure fluctuations and better play the role of oil drainage in the low permeability zone. However, the water injection rate of a reservoir does not increase indefinitely, so cyclic 
adjustment of the water injection rate and liquid rate within the allowable maximum water injection rate and maximum extraction volume can achieve the purpose of improving the development effect.

\section{Conclusions}

(1) In the late stage of water injection development for high-saturated reservoirs, affected by the gas-oil ratio, the formation pressure maintenance level must be higher to maintain the same pump efficiency as conventional reservoirs.

(2) When the injection-production ratio is low, the pressure recovery speed is slow, which is not conducive to the stable production of the reservoir. When the injection-production ratio is too large, the water cut rises quickly and the water injection utilization rate is low. Therefore, there is a reasonable interval for the injectionproduction ratio.

(3) Under the constraints of the maximum liquid extraction volume and the maximum water injection volume, cyclic and large adjustments to the water injection volume and liquid production volume can improve the water flooding development effect. The effect of cyclic injection-production is better than cyclic water injection, which plays a significant role in improving the development effect of water-flooding in high-saturated reservoirs at the late stage.

\section{References}

1. M.F. Chen, M.P. Meng, M. Wang, J. Gai, J.H. Shi(2014) Study on reasonable energy supplement timing for low permeability and high saturation reservoirs. Fault-Block Oil \& Gas Field, 21(4):463-466.

2. J. Huo, L.X. Sang, G.X. Shi, J.G. Lu, K.C. Zhao(2011) Research on Efficient Development Technology for Lithologic Reservoir with Low Permeability and High Saturation-An example from Shinan-21 Wellblock. Xinjiang Petroleum Geology, 32(6):624-626.
3. M.F. Chen, G.L. Liu, D.S. Sun, X.M. Tang, W. Zhen(2011) Reasonable injection-production policies of water flooding in high-saturated reservoir. Complex Hydrocarbon Reservoirs, 4(4):37-58.

4. M.H. Cui, B. Yang, C.G. Qu, G.J. Shi, X.M. Li, C $\mathrm{Lu}(2008)$ Countermeasures for improving development effect of high-saturated reservoir by water flood. Fault-Block Oil \& Gas Field, 15(5):65-68.

5. Y.L. Wen, Z.M. Du(2004) Effect of Gas Injection on Saturation Pressure of Volatile Reservoirs. Xinjiang Petroleum Geology, 25(5):520-522.

6. W.F. Huang, X.J. Qin, X.Y. Du(2012) Study on Development Effectiveness of Water Injection and Gas Injection for Reservoirs With Low Volatile Black Oil. Petroleum Geology and Recovery Efficiency, 19(4):87-89.

7. B.Q. Yang, Z.W. Yuan, L. Yang, Y.F. Luo, W.H. $\mathrm{Gu}$, J.F. Shang(2013) Forecast Model of Development Index for Natural Gas Injection in Volatile Reservoir. Reservoir Evaluation and Development, 3(6):19-23.

8. L. Chen, L. Sun, X.H. Liu, D. Chen, X. Le, L. Bai(2014) Study on Mechanism and Experimental Results of Gas Injection Flooding of KKY $-\mathrm{X}_{5}^{2}$ Volatile Oil Field. Reservoir Evaluation and Development, 4(3):43-49.

9. D.S. Lei, Z.M. Du, Y. Fu, Y Zhang(2010) The Research of Mechanism if Imbibition Process in Cyclic Water Injection. Journal of Southwest Petroleum University (Science \& Technology Edition) 32(1):101-104.

10. J.C. Zhang, S.Z. Bai, Y.J. Zhang, Y.H. Ban(2003) Cyclic Water Flooding Experiments and Research on Mechanism of Enhancing Oil Production. ACTA PETROLEI SINICA, 24(2):76-80.

11. Z.H. Chen, Z.M. Du(1997) The Cyclic Water Flooding Numerical Simulation for Its Seepage Mechanism and Effective Factors. Journal of Southwest Petroleum Institute 19(3):54-63. 